Please cite as:

Vandenbosch, L., Beyens, I., Vangeel, L., \& Eggermont, S. (in press). Online Communication

Predicts Belgian Adolescents' Initiation of Romantic and Sexual Activity. European Journal of Pediatrics.

\title{
Online Communication Predicts Belgian Adolescents' Initiation of Romantic and Sexual Activity
}

\author{
Laura Vandenbosch ${ }^{1,2}, \mathrm{PhD}$, Ine Beyens ${ }^{1}, \mathrm{MS}$, Laurens Vangeel, $\mathrm{MS}^{1}$, Steven Eggermont ${ }^{1}$, \\ $\mathrm{PhD}$
}

Affiliations: ${ }^{1}$ Leuven School for Mass Communication Research, Faculty of Social Sciences, University of Leuven, Leuven, Belgium; ${ }^{2}$ Research Foundation Flanders (FWO-Vlaanderen) and MIOS (Media, ICT, and Interpersonal Relations In Organisations and Society), University of Antwerp.

Email addresses: laura.vandenbosch@soc.kuleuven.be, ine.beyens@soc.kuleuven.be, laurens.vangeel@soc.kuleuven.be, steven.eggermont@soc.kuleuven.be

Address correspondence to: Laura Vandenbosch, Leuven School for Mass Communication Research, Faculty of Social Sciences, University of Leuven, Parkstraat 45 (PO box 3603), B3000 Leuven, Belgium. E-mail: laura.vandenbosch@ soc.kuleuven.be Tel: + 3216323202

Short title: Online communication in adolescents

Acknowledgements. The authors would like to acknowledge and thank the Research Foundation Flanders (Fonds Wetenschappelijk Onderzoek, Vlaanderen) for their financial support to the study. 


\section{What is Known}

- Adolescents increasingly communicate online with peers.

- Online communication predicts romantic and sexual activity among college students.

\section{What is New}

- Online communication predicts adolescents' offline romantic activity over time.

- Online communication predicts adolescents' offline sexual activity over time. 


\begin{abstract}
Online communication is associated with offline romantic and sexual activity among college students. Yet, it is unknown whether online communication is associated with the initiation of romantic and sexual activity among adolescents. This two-wave panel study investigated whether chatting, visiting dating websites, and visiting erotic contact websites predicted adolescents' initiation of romantic and sexual activity. We analyzed two-wave panel data from 1,163 Belgian adolescents who participated in the MORES Study. We investigated the longitudinal impact of online communication on the initiation of romantic relationships and sexual intercourse using logistic regression analyses. The odds ratios of initiating a romantic relationship among romantically inexperienced adolescents who frequently used chat rooms, dating websites, or erotic contact websites were two to three times larger than those of non-users. Among sexually inexperienced adolescents who frequently used chat rooms, dating websites, or erotic contact websites, the odds ratio of initiating sexual intercourse was two to five times larger than among non-users, even after a number of other relevant factors were introduced.

Conclusion: This is the first study to demonstrate that online communication predicts the initiation of offline sexual and romantic activity as early as adolescence. Practitioners and parents need to consider the role of online communication in adolescents' developing sexuality.
\end{abstract}




\section{Key Words}

Adolescent sexuality; chat rooms; dating websites; erotic contact websites; online communication.

\section{Abbreviations}

No abbreviations were used. 


\section{Introduction}

One of the notable lacunae in research on adolescents' romantic and sexual relationships is the limited insight in the role of online communication. This is remarkable given that adolescents communicate through online tools on a daily basis [20] and more frequently than any other age group [9, 18]. Moreover, recent studies have suggested that online communication through visiting chat rooms, dating websites, or erotic contact websites (i.e., websites where users can contact each other to have offline and online sex), may play a role in adolescents' (offline) romantic and sexual behavior [4, 33].

It is clear that chat rooms, dating websites, and erotic contact websites offer endless opportunities to connect sexually and/or romantically with others $[5,7,34]$ relatively free from spatial, social, and even appearance-related constraints [28, 34]. This may be especially appealing for teens given the central position of sexual and romantic processes in adolescent development [35] and the difficulty to communicate about sexuality and romantic feelings with parents and educators [8]. As online communication combines the advantages of communicating with peers and staying anonymous, it is no surprise that adolescents frequently discuss sexual topics with (mostly unknown) peers in chat boxes [34] and visit erotic contact websites [27].

Adolescents may not only discuss sexual and romantic issues within the online context $[6,29,34]$, they may also use online communication as a vicarious learning environment in which they experiment with their sexuality before engaging in actual offline sexual and romantic activities [4]. A limited number of cross-sectional studies in college students $[6,12]$ has supported this suggestion and showed associations between online sexual and romantic communication and offline sexual experience, such as an increased number of sexual partners.

However, it is currently unclear whether online communication would predict offline sexual and romantic experiences as early as adolescence. Nevertheless, knowledge on whether 
online communication already plays a role in adolescent sexual and romantic development is important; for instance, because literature has stressed that early sexual and romantic behaviors likely set the stage for future sexual and romantic trajectories [23, 35]. Both health organizations $[2,11,38]$ and scholars $[31,32,37]$ have called for continued scholarly attention to factors that play a role in the initiation of sexual and romantic behaviors, as such understanding can guide education and prevention efforts that provide adolescents with the necessary knowledge and skills. In addition, scholars have criticized online communication for often reflecting a biased interpretation of romance and sexuality [15]. For instance, sexual gender stereotypes often occur in online communication $[15,33]$. For these reasons, this twowave panel study in 12- to 18-year-olds addressed the extent to which online communication (i.e., visiting chat rooms, visiting dating websites, and visiting erotic contact websites) predicts the formation of a romantic relationship in romantically inexperienced adolescents and the initiation of sexual intercourse in sexually inexperienced adolescents.

\section{Sample and Procedure}

\section{Methods}

A school-based, two-wave study was conducted in 2010. A representative sample of boys and girls aged 12 to 18 years old was recruited from 12 schools in different regions of Flanders (the Dutch-speaking part of Belgium). Trained research assistants visited the schools and distributed paper surveys at both waves. All adolescents completed the survey at school during school hours. Adolescents had two hours to complete the survey, were allowed to take a break, and were encouraged to ask questions when items were unclear or when they were uncertain of the meaning of an item. No incentive was provided as this is not customary in Belgium. A six-month interval was established because of the relatively rapid sequence of developmental changes occurring during adolescence [25]. Approval for the survey was granted by the institutional review board of the host university. Informed consent was obtained in accordance with the customary guidelines in Belgium. To increase confidentiality, 
researchers ensured that other people could not see the respondents' answers, and data were de-identified before being processed.

\section{Measures}

Use of chat rooms and dating websites. Respondents indicated on an 8-point scale how often they usually visit chat rooms [39] (never $=1$ through all day long $=8$ ) and dating websites [28] (never $=1$ through all day long $=8)$.

Use of erotic contact websites. Respondents indicated on a 7-point scale (never $=1$ through several times a day $=7$ ) how often during the last six months they had intentionally exposed themselves to erotic contact sites [27]. This question differed from the other Internet questions because of the more sexually explicit nature of the medium; the option "throughout the whole day" was omitted and the option "during the last 6 months" was added to ensure recent use of such websites was measured.

Romantic relationship formation. At Time 2, respondents who were romantically inexperienced at Time 1 indicated whether they were involved in a romantic relationship or $\operatorname{not}($ no $=0 ;$ yes $=1)[28]$.

Sexual initiation. At Time 2, respondents who were sexually inexperienced at Time 1 indicated whether they had ever had sexual intercourse (no $=0 ;$ yes $=1)$ [36].

Control variables. A number of covariates that could confound the relationships under scrutiny were included. Research has suggested that gender [21, 22, 26], age [21, 22], quality of communication with parents [21, 24], and quality of communication with peers [10, $21,37]$ are related to sexual and romantic outcomes in adolescents.

To measure communication with peers and parents, respondents indicated their agreement with items from the Inventory of Peer and Parent Attachment [3] on a five-point scale from never true $(=1)$ to always true $(=5)$. For peers, the nine items with the highest factor loadings on the Communication factor in the original study were selected. However, the item "My 
friends accept me as I am" was replaced by the item "My friends understand me", as the latter explicitly refers to communication quality. An average score was calculated ( $\alpha=.91)$. For parents, the 7 items with the highest factor loadings in the original study were selected (the item "I feel it's no use letting my feelings show" was excluded because the item did not directly refer to parents). We also included the items "My parents understand me" and "When we discuss things, my parents consider my point of view." An average score was calculated $(\alpha=.89)$.

\section{Statistical Analyses}

Mean values, frequencies, cross-tables, and zero-order correlations were calculated. Logistic regression analyses were conducted to predict romantic relationship formation in respondents who had not been in a romantic relationship at baseline and initiation of sexual intercourse in respondents who had not yet been sexually active at baseline. Separate regression models were run for each of the three online communication behaviors. The variables of chat, dating, and erotic contact websites were recoded to distinguish non-users $(=1)$ from infrequent $(=2$; less than once a month) and frequent (= 3 ; monthly to daily) users. All analyses controlled for baseline values of control variables. Furthermore, because prior research has suggested that age and gender may moderate the relationships under scrutiny [37], moderation analyses were conducted. To this end, a dichotomous variable of age (group $1=12$ - to 15 -year-olds; group $2=16$ - to 18 -year-olds) was created. Because "casewise" deletion for missing data has been criticized [1], all available data of students who had completed the questionnaires at baseline and follow-up were included. As such, dropouts were excluded and students who had participated in both questionnaires but had missing data were included.

\section{Results}

\section{Subjects}


A total of 1,504 students completed the questionnaire at baseline; 1,163 of them (77.3\%) completed the questionnaires for both waves. The mean age was 15.36 years $(S D=$ 1.47; range 12-18). Ninety five percent of the respondents (95.0\%) were born in Belgium, $56.5 \%$ were boys, $62.5 \%$ were following a general educational program, which is representative of the overall school population $(62.6 \% ;[13])$.

A MANOVA analysis compared whether the scores on key variables at Wave 1 differed between adolescents who had only participated in Wave 1 and those who had participated in both waves of the study. Only adolescents without missing data at baseline for age, communication with parents, communication with peers, gender, use of chat, dating, and erotic contact websites, sexual initiation and romantic relationship status were included in this analysis (see Table 1). Dropouts showed a lower level of communication with parents and higher scores on usage of dating sites, chat rooms, and erotic contact websites. In addition, boys, adolescents who had a romantic relationship, and adolescents who had engaged in sexual intercourse were significantly more likely to drop out.

\section{Descriptive Data}

Of the 1,163 students who completed both questionnaires, 940 were virgins at Time 1 $(81.2 \%)$ and 889 were not involved in a romantic relationship at Time 1 (77.4\%). At followup, $9 \%$ of the virgins at baseline indicated that they had initiated sexual intercourse within the six-month period of the study and $15.7 \%$ of the singles at baseline indicated that they were involved in a relationship six months later.

Furthermore, of the 1,163 students who completed the questionnaires at both waves, one in five (20.2\%) identified themselves as frequent users of at least one of the online communication tools under scrutiny. About one in six frequently visited chat rooms $(16.8 \%)$ and another $7.0 \%$ visited such websites infrequently. Furthermore, while $3.3 \%$ of the students identified themselves as infrequent users of dating sites, $2.8 \%$ of the students reported they 
were frequent users. Regarding erotic contact websites, $4.4 \%$ of the students were frequent users and $4.2 \%$ students were infrequent users.

Proportions of romantic relationship formation (Time 2) across online communication frequency categories (Time 1) among singles at baseline $(N=889)$ revealed that approximately one third of the frequent visitors of dating websites $(33.3 \%)$ and one fourth of the frequent visitors of chat rooms (22.9\%) and erotic websites $(22.5 \%)$ had formed a romantic relationship at Time 2 . This analysis also showed that about $15 \%$ of the non-users of dating websites (14.7\%), chat rooms (14.5\%), and erotic websites (15.5\%) were involved in a romantic relationship at Time 2. A similar analysis among virgins at baseline $(N=940)$ revealed that about one in ten of the frequent visitors of chat rooms $(11.3 \%)$, one in six of the frequent visitors of dating websites (17.4\%), and approximately one in five of the frequent visitors of erotic websites $(22.4 \%)$ had initiated sexual intercourse at Time 2. Less than one in ten non-users of dating websites $(8.9 \%)$, chat rooms $(8.3 \%)$, and erotic websites $(8.2 \%)$ had engaged in sexual intercourse at Time 2 .

Table 2 presents the zero-order correlations between all relevant variables.

\section{Romantic Relationship Formation}

Results (see Table 3, $N=889$ ) indicated that the use of chat rooms, dating and erotic contact websites significantly predicted romantic relationship formation over time. The odds ratio for adolescents who frequently used chat rooms was two times larger than those of adolescents who never visited these websites. The odds ratio of having a romantic partner after six months was three to four times larger among frequent users of erotic contact websites and of dating websites than among non-users. Neither age nor gender moderated the relationships.

\section{Initiation of Sexual Intercourse}


Results (see Table $4, N=940$ ) indicated that the odds ratio of initiating sexual intercourse after six months was almost two times larger among adolescents who frequently used chat rooms than among adolescents who never visited online chat rooms, though this odds ratio was only marginally significant. The odds ratio of initiating sexual intercourse after six months was three times larger among frequent users of dating websites and almost six times larger among frequent users of erotic contact websites compared with non-users. Neither age nor gender moderated the relationships.

\section{Discussion}

The current study is the first, to our knowledge, to demonstrate that online communication is longitudinally associated with romantic relationship formation and initiation of sexual intercourse in adolescents, independent of other relevant factors. The odds ratio of initiating a romantic relationship was twice as large among frequent users of chat rooms than among non-users, and the odds ratio of initiating a romantic relationship was more than three times larger among frequent users of dating and erotic contact websites than among non-users. Furthermore, the odds ratio of initiating sexual intercourse was twice as large among frequent users of chat rooms, three times larger among frequent users of dating websites, and more than five times larger among frequent users of erotic contact websites than among non-users.

There are several key contributions of the current study. This study extends prior research that has informed us on the consequences of online communication in college

students [e.g., 6], by showing that adolescents' sexual and romantic activities are also affected by their online activities. Moreover, the longitudinal findings support the temporal order that has been suggested by prior cross-sectional findings on online communication and sexual behavior [e.g., 12] and demonstrate that online sexually-oriented communication predicts offline sexual and romantic activities over time. 
The current longitudinal findings suggest that adolescents use online communication as a vicarious learning environment to explore their own sexuality and romantic feelings. Importantly, prior literature has demonstrated that online interactions tend to neglect the complexity that is inherently related to face-to-face romantic and sexual interactions, to enhance short-term instead of long-term relationships, and to reflect gender-stereotypical sexual norms that support a female passive submissive role and a male active dominant role [15]. While online communication appears to allow adolescents to experiment with their sexuality before engaging in actual offline sexual and romantic activities, it may at the same time hinder adolescents to engage in authentic, rewarding sexual and romantic interactions. Future research is needed to explore this issue.

In addition, research may examine which mechanisms explain why online communication stimulates romantic and sexual activity among adolescents. Prior literature on the effects of sexual entertainment media use suggests that changes in attitudes and perceived peer norms regarding sexuality and dating may play an important role in these processes [37]. Furthermore, the revealed findings are useful for the development of effective health communication campaigns. In particular, they provide guidance with respect to the selection of audience segments and intervention tools. Because frequent users of sexually-oriented online communication were found to have greater odds of initiating romantic and sexual activity, education and prevention campaigns are recommended to target the segment of adolescents that frequently communicates online through chat boxes, dating websites, and/or erotic contact websites. In the current study, this segment contained $20.2 \%$ of the students. As such, the identified segment seems substantial enough in size to make an intervention worthwhile $[14,16]$. Moreover, this finding is in line with prior research among other European adolescents [5]. An intervention can prepare the targeted adolescents for their very first sexual and romantic experiences by equipping them with the skills and knowledge 
necessary to successfully address future challenges. More precisely, an intervention may stimulate adolescents (1) to especially explore the positive dimensions of sexuality and committed relationships, such as sexual satisfaction and the experience of being loved, (2) to avoid negative aspects of sexuality, such as contracting a sexually transmitted disease, and (3) to develop skills to handle relationship conflicts $[17,19,30,35]$. Also, parents and educators need to be informed about the possibility to identify adolescents with an increased likelihood of becoming sexually and romantically active by their usage of chat rooms, dating and erotic contact websites.

Moreover, as the current study findings support the notion that online media provide a vicarious learning environment for offline sexual and romantic behaviors [4], future education and prevention research needs to consider online media environments as potentially powerful intervention tools. The media landscape has changed considerably during the last decade. The current study suggests that these changes have provided us with new tools to approach, inform, and educate adolescents on sexuality and romantic developmental issues. Sexual health practitioners are thus advised to expand their use of traditional media platforms (e.g., television and print media) in health interventions with online media platforms (e.g., chat rooms, dating websites, and erotic contact websites accessed through computers, smartphones, and tablets). Moreover, these new, interactive media provide new features that may be especially useful within the context of sexual health communication (e.g., interactivity with the possibility of remaining anonymous) [27; 34]. As such, technology-based online sexual health education might be useful to help adolescents develop and experiment in healthy ways.

\section{Limitations}

The study was strengthened by its longitudinal design, but limited by a loss to followup. Dropouts were more frequent users of chat rooms, dating websites, and erotic contact 
websites, and were more experienced in sexual and romantic behavior. This could have led to an underestimation of the influence of adolescents' online communication. Also, although we included several covariates in the analytical models, it is possible that residual confounding by other factors, such as pubertal status [22], accounted for the reported results. Moreover, future research should have attention for potential moderating factors. For instance, educational background has been related to increased exposure to online risky sexual content [4] and to increased sexual activity [22]. In addition, the study focused on Belgian adolescents. Different results may be found among adolescents from other countries.

\section{Conclusion}

The current study demonstrates that online communication is an important factor in adolescents' initiation of sexual intercourse and formation of romantic relationships. Health practitioners, educators, and parents are recommended to screen for adolescents with a high likelihood of becoming sexually and romantically active by their level of online communication. Moreover, the potential of online media platforms to provide anticipatory guidance in regard to a healthy sexual development needs to be considered in future research. As such, adolescents will become more resilient toward potential challenges associated with exploratory romantic and sexual behaviors. 


\section{Compliance with Ethical Standards}

Funding source. The study was funded by the Research Foundation Flanders (FWO, Vlaanderen, 1.1.452.10.N.00).

Disclosure of potential conflict of interest: Author Laura Vandenbosch declares that she has no conflict of interest. Author Ine Beyens declares that she has no conflict of interest. Author Laurens Vangeel declares that he has no conflict of interest. Author Steven Eggermont declares that he has no conflict of interest.

Ethical approval for research involving human participants: All procedures performed in the present study were in accordance with the ethical standards of the institutional research committee and with the national guidelines at the time of the study. These guidelines formulate ethical standards comparable to the 1964 Helsinki declaration and its later amendments, but applied to social science research.

Informed consent: The research involved human participants. Informed consent was obtained from the legal guardians of all participants included in the study. 


\section{References}

1. Allison PD (2003) Missing data techniques for structural equation modeling. J. Abnorm. Psychol 112:545-557. doi:10.1037/0021-843X.112.4.545.

2. American Academy of Pediatrics (2010) Policy statement: sexuality, contraception, and the media. Pediatrics 126:576-582. doi: 10.1542

3. Armsden GC, Greenberg MT (1987) The inventory of parent and peer attachment: Individual differences and their relationship to psychological well-being in adolescence. J Youth Adolesc 16:427-54. doi:10.1007/BF02202939.

4. Baumgartner SE, Sumter SR, Peter J, Valkenburg PM (2012) Identifying teens at risk: developmental pathways of online and offline sexual risk behavior. Pediatrics 130:e1489-1496. doi:10.1542/peds.2012-0842.

5. Beyens I, Eggermont S (2014) Prevalence and predictors of text-based and visually explicit cybersex among adolescents. Young 22:43-65.

doi:10.1177/0973258613512923.

6. Boies SC (2002) University students uses of and reactions to online sexual information and entertainment: Links to online and offline sexual behavior. Can J Hum Sex 11:77-89.

7. Bouchey HA, Furman W (2003) Dating and romantic experiences in adolescence. In: Adams GR, Berzonsky M (ed) The Blackwell Handbook of Adolescence. Oxford, Blackwell Publishers, UK, pp 312-329

8. Buckingham D, Bragg S (2004) Young People, Sex and the Media. The Facts of Life? Palgrave Macmillan, London

9. Centraal Bureau voor de Statistiek (2014) ICT gebruik van personen naar persoonskenmerken. Centraal bureau voor statistiek. Available at: http://statline.cbs.nl/Statweb/publication/?DM=SLNL\&PA=71098ned\&D1=33,55- 
$59,93-95,97-100,102-104,106-109,112-113,119,124-133 \& D 2=0,3 \& D 3=0,7-$ $8 \& \mathrm{HDR}=\mathrm{G} 2, \mathrm{G} 1 \& \mathrm{STB}=\mathrm{T} \& \mathrm{VW}=\mathrm{T}$.

10. Crockett LJ, Bingham CR, Chopak JS, Vicary JR (1996) Timing of first sexual intercourse : The role of social control, social learning, and problem behavior. J Youth Adolesc 25:89-111. doi:10.1007/BF01537382.

11. Currie C, Hurrelmann K, Settertobulte W, Smith R, Todd J (2000) Health and Health Behaviour among Young People. WHO, Copenhagen

12. Daneback K, Cooper A, Månsson S-A (2005) An Internet study of cybersex participants. Arch Sex Behav 34:321-328. doi:10.1007/s10508-005-3120-z.

13. Education Department of Flanders (2011) Statistisch Jaarboek van Het Vlaams Onderwijs, Schooljaar 2010_2011. [Statistical Yearbook of Flemish Education, Academic Year 2010_2011] Departement van Onderwijs, Brussel

14. Fishbein M, Yzer MC (2003) Using theory to design effective health behavior interventions. Commun Theory 13:164-183. doi:10.1111/j.1468-2885.2003.tb00287.x.

15. Henry-waring M, Barraket J, Sciences P (2008) Dating \& intimacy in the 21st century: The use of online dating sites in Australia. Int J Emerg Technol Soc 6:14-33.

16. Hornik R, Woolf KD (1999) Using cross-sectional surveys to plan message strategies. Soc Mar Q 5:34-41.

17. Impett EA, Muise A, Breines JG (2013) From risk to pleasure: Toward a positive psychology of sexuality. In: Hojjat M, Cramer D (ed) Positive psychology of love. Oxford University Press, New York, pp 57-76.

18. Jones S, Fox S (2009) Generations online in 2009. Pew Research Center. Available at: website http://www.pewinternet.org/Reports/2009/Generations-Online-in-2009.aspx.

19. Joyner K, Udry JR (2000) You don't bring me anything but down: Adolescent romance and depression. J Health Soc Behav 41:369-391. 
20. Koutamanis M, Vossen HGM, Peter J, Valkenburg PM (2013) Practice makes perfect: The longitudinal effect of adolescents' instant messaging on their ability to initiate offline friendships. Comput Human Behav 29:2265-2272. doi:10.1016/j.chb.2013.04.033.

21. L'Engle KL, Brown JD, Kenneavy K (2006) The mass media are an important context for adolescents' sexual behavior. J Adolesc Health 38:186-192. doi:10.1016/j.jadohealth.2005.03.020.

22. L’Engle KL, Jackson C. (2008) Socialization influences on early adolescents' cognitive susceptibility and transition to sexual intercourse. J Res Adolesc. 18:353378. doi:10.1111/j.1532-7795.2008.00563.x.

23. Miller BC, Moore KA (2009) Adolescent sexual behavior, pregnancy, and parenting: Research through the 1980s. J Mar Fam 52:1025-1044.

24. Miller BC, Norton MC, Fan X, Christopherson CR (1998) Pubertal development, parental communication, and sexual values in relation to adolescents' sexual behaviors. J Early Adolesc 18:27-52. doi:10.1177/0272431698018001002.

25. Mul D (2004) Puberteitsontwikkeling van Nederlandse kinderen [Pubertal development of Dutch children]. Tijdschr voor Seksuol. 28:82-86.

26. Oliver MB, Hyde JS (1993) Gender differences in sexuality: A meta-analysis. Psychol Bull 114:29-52. doi:10.1037/0033-2909.114.1.29.

27. Peter J, Valkenburg PM (2006) Adolescents' exposure to sexually explicit material on the Internet. Communic Res 33:178-204. doi:10.1177/0093650205285369.

28. Peter J, Valkenburg PM (2007) Who looks for casual dates on the Internet? A test of the compensation and the recreation hypothesis. New Media Soc 9:105-124. doi: $10.1177 / 1461444807076975$ 
29. Pew Internet \& American Life Project (2001) The rise of the instant-message generation and the internet's impact on friendships and family relationships teenage life online. Pew Research Center. Available at: http://www.pewinternet.org/reports/ pdfs/PIP_Teens_Report.pdf.

30. Pinkleton BE, Austin EW, Cohen M, Chen Y-CY, Fitzgerald E (2008) Effects of a peer-led media literacy curriculum on adolescents' knowledge and attitudes toward sexual behavior and media portrayals of sex. Health Commun 23:462-472. doi:10.1080/10410230802342135.

31. Strasburger VC, Jordan AB, Donnerstein E (2010) Health effects of media on children and adolescents. Pediatrics 125:756-767. doi:10.1542/peds.2009-2563.

32. Strasburger VC (2013) Spinal column: why isn't there more media research? Clin Pediatr 52:587-588. doi:10.1177/0009922813476343.

33. Subrahmanyam K, Greenfield P (2008) Online communication and adolescent relationships. Futur Child Child Media Technol 18:119-146.

34. Subrahmanyam K, Smahel D, Greenfield P (2006) Connecting developmental constructions to the internet: identity presentation and sexual exploration in online teen chat rooms. Dev Psychol 42:395-406. doi:10.1037/0012-1649.42.3.395.

35. Tolman DL, McClelland SI (2011) Normative sexuality development in adolescence: A decade in review, 2000-2009. J Res Adolesc 21:242-255. doi:10.1111/j.15327795.2010.00726.x.

36. Vandenbosch L, Eggermont S (2012) Sexually explicit websites and sexual initiation: Reciprocal relationships and the moderating role of pubertal status. J Res Adolesc 23:621-634. doi:10.1111/jora.12008. 
37. Ward L (2003) Understanding the role of entertainment media in the sexual socialization of American youth: A review of empirical research. Dev Rev 23:347388. doi:10.1016/S0273-2297(03)00013-3.

38. WHO. HEALTH21 (1999) The health for all policy framework for the WHO European Region. WHO. Available at: http://www.euro.who.int/_data/assets/pdf_file/0010/98398/wa540ga199heeng.pdf. 39. Ybarra ML, Mitchell KJ, Wolak J, Finkelhor D (2006) Examining characteristics and associated distress related to Internet harassment: Findings from the Second Youth Internet Safety Survey. Pediatrics 118:e1169-1177. doi:10.1542/peds.2006-0815. 
ONLINE PORNOGRAPHY, SEXUAL INITIATION, PUBERTY

Table 1. MANOVA analysis on differences between adolescents participating in one wave $(N=254)$ and those participating in both waves with no missing data at baseline $(N=1,006)$.

\begin{tabular}{lllr}
\multicolumn{1}{c}{ Variable } & \multicolumn{1}{c}{$F$-statistic } & Dropouts & Adolescents participating in both waves \\
& & $M(S D)$ & $M(S D)$ \\
\hline Communication with parents & $F(1,1258)=4.43, p=.036, \eta p^{2}=.01$ & $3.05(0.86)$ & $1.16(0.72)$ \\
Gender & $F(1,1258)=22.54, p<.001, \eta p^{2}=.02$ & $1.28(0.45)$ & $1.45(0.50)$ \\
Usage of dating sites & $F(1,1258)=12.81, p<.001, \eta p^{2}=.01$ & $1.33(1.15)$ & $1.13(0.66)$ \\
Usage of chat rooms & $F(1,1258)=8.13, p=.004, \eta p^{2}=.01$ & $2.11(2.02)$ & $1.76(1.67)$ \\
Usage of erotic contact websites & $F(1,1258)=6.27, p=.012, \eta p^{2}=.01$ & $1.30(0.97)$ & $.33(0.47)$ \\
Romantic relationship & $F(1,1258)=12.00, p=.001, \eta p^{2}=.01$ & $.28(0.45)$ & $.23(0.42)$ \\
Sexual initiation & $F(1,1258)=10.32, p=.001, \eta p^{2}=.01$ & $.19(0.39)$
\end{tabular}


ONLINE PORNOGRAPHY, SEXUAL INITIATION, PUBERTY

Table 2. Zero-order correlations between relevant variables $(N=1,163)$.

14

\begin{tabular}{|c|c|c|c|c|c|c|c|}
\hline & $\begin{array}{c}\text { Chat rooms } \\
\text { T1 }\end{array}$ & $\begin{array}{c}\text { Dating } \\
\text { websites T1 }\end{array}$ & $\begin{array}{c}\text { Erotic contact } \\
\text { websites } \mathrm{T} 1\end{array}$ & $\begin{array}{c}\text { Romantic } \\
\text { relationship } \\
\text { T1 } \\
\end{array}$ & $\begin{array}{c}\text { Romantic } \\
\text { relationship T2 }\end{array}$ & $\begin{array}{c}\text { Sexual } \\
\text { initiation T1 }\end{array}$ & $\begin{array}{c}\text { Sexual } \\
\text { initiation } \mathrm{T} 2\end{array}$ \\
\hline Chat rooms $\mathrm{T} 1$ & 1 & $.23^{* * * *}$ & $.15^{* * *}$ & .04 & $.08^{* *}$ & -.01 & .02 \\
\hline Dating websites T1 & & 1 & $.27^{* * * *}$ & .01 & $.08^{*}$ & .02 & .03 \\
\hline Erotic contact websites T1 & & & 1 & -.02 & .02 & .02 & $.06^{*}$ \\
\hline Romantic relationship T2 & & & & & 1 & $.37^{* * *}$ & $.47^{* * *}$ \\
\hline Sexual initiation $\mathrm{T} 1$ & & & & & & 1 & $.78^{* * *}$ \\
\hline Sexual initiation T2 & & & & & & & 1 \\
\hline
\end{tabular}

Note. ${ }^{*} p<.05 ;{ }^{* *} p<.01 . ;{ }^{* * *} p<.001$ 
ONLINE PORNOGRAPHY, SEXUAL INITIATION, PUBERTY

Table 3. Logistic regression analyses in 889 single adolescents at Time 1.

\begin{tabular}{|c|c|c|c|c|c|c|}
\hline \multirow[t]{2}{*}{ Romantic relationship formation $\mathrm{T} 2$} & \multicolumn{2}{|c|}{ Model 1: Chat rooms } & \multicolumn{2}{|c|}{ Model 2: Dating websites } & \multicolumn{2}{|c|}{ Model 3: Erotic contact websites } \\
\hline & $\begin{array}{c}\text { Regression } \\
\text { Coefficient } \\
\quad(S E)\end{array}$ & OR $(95 \% C I)$ & $\begin{array}{c}\text { Regression } \\
\text { Coefficient } \\
(S E)\end{array}$ & OR $(95 \% C I)$ & $\begin{array}{c}\text { Regression } \\
\text { Coefficient } \\
\quad(S E)\end{array}$ & OR $(95 \% C I)$ \\
\hline Age T1 & $.16(.08)^{*}$ & $1.17(1.01-1.36)$ & $.14(.08)^{\dagger}$ & $1.15(0.99-1.33)$ & $.14(.07)^{\dagger}$ & $1.15(.99-1.33)$ \\
\hline Communication with parents $\mathrm{T} 1$ & $-.40(.15)^{* *}$ & $0.67(0.50-0.90)$ & $-.36(.15)^{*}$ & $0.70(0.52-0.93)$ & $-.41(.15)^{* *}$ & $.66(.50-.88)$ \\
\hline Communication with peers $\mathrm{T} 1$ & $.74(.18)^{* * *}$ & $2.1(1.47-3.01)$ & $.81(.19)^{* * *}$ & $2.24(1.56-3.22)$ & $.77(.18)^{* * *}$ & $2.15(1.51-3.07)$ \\
\hline Gender T1 (boys ref) & $.23(.23)$ & $1.26(0.81-1.97)$ & $.19(.23)$ & $1.21(0.77-1.89)$ & $.28(.23)$ & $1.32(.84-2.08)$ \\
\hline \multicolumn{7}{|l|}{ Online predictor $\mathrm{T} 1$ (ref non-users) } \\
\hline Infrequent users & $-.16(.46)$ & $0.85(0.35-2.10)$ & $.42(.53)$ & $1.52(0.54-4.28)$ & $.44(.53)$ & $1.55(.54-4.40)$ \\
\hline Frequent users & $.87(.26)^{* * *}$ & $2.39(1.44-3.96)$ & $1.27(.53)^{*}$ & $3.57(1.28-9.99)$ & $1.17(.43)^{* *}$ & $3.21(1.39-7.43)$ \\
\hline Model constant & $-5.71(1.38)$ & .00 & $-5.67(1.38)$ & .00 & $-5.34(1.36)$ & .00 \\
\hline
\end{tabular}

$30 \quad$ Note. $^{\dagger}<.10 * p<.05 ; * * p<.01 ; * * p<.001$; Model of chat rooms $\chi^{2}(6)=46.12, p<.001$; Model of dating websites $\chi^{2}(6)=42.28, p<.001$;

$31 \quad$ Model of erotic contact websites $\chi^{2}(6)=42.66, p<.001$ 
ONLINE PORNOGRAPHY, SEXUAL INITIATION, PUBERTY

Table 4. Logistic regression analyses in 940 virgins at Time 1.

34

\begin{tabular}{|c|c|c|c|c|c|c|}
\hline \multirow[t]{2}{*}{ Sexual initiation T2 } & \multicolumn{2}{|c|}{ Model 1: Chat rooms } & \multicolumn{2}{|c|}{ Model 2: Dating websites } & \multicolumn{2}{|c|}{ Model 3: Erotic contact websites } \\
\hline & Regression & OR $(95 \% C I)$ & Regression & OR $(95 \% C I)$ & Regression & OR $(95 \% C I)$ \\
\hline & Coefficient & & Coefficient & & Coefficient & \\
\hline & $(S E)$ & & $(S E)$ & & $(S E)$ & \\
\hline Age T1 & $0.44(.10)^{* * *}$ & $1.55(1.26-1.89)$ & $0.42(.10)^{* * *}$ & $1.52(1.24-1.86)$ & $0.43(.10)^{* * *}$ & $1.54(1.26-1.88)$ \\
\hline Communication with parents $\mathrm{T} 1$ & $-0.35(.17)^{*}$ & $0.71(.50-.99)$ & $-0.37(.17)^{*}$ & $0.69(.49-.97)$ & $-0.36(.17)^{*}$ & $0.69(.49-.98)$ \\
\hline Communication with peers $\mathrm{T} 1$ & $0.60(.21)^{* *}$ & $1.83(1.21-2.77)$ & $0.62(.21)^{* *}$ & $1.86(1.23-2.83)$ & $0.66(.21)^{* *}$ & $1.93(1.27-2.95)$ \\
\hline Gender T1 (boys ref) & $-0.36(.27)$ & $0.70(.41-1.19)$ & $-0.38(.28)$ & $0.69(.40-1.18)$ & $-0.22(.28)$ & $0.80(.46-1.39)$ \\
\hline \multicolumn{7}{|l|}{ Online predictor T1 (ref non-users) } \\
\hline Infrequent users & $0.34(.44)$ & $1.40(.60-3.30)$ & $-0.68(1.05)$ & $0.51(.07-3.95)$ & $0.67(.58)$ & $1.95(.63-6.06)$ \\
\hline Frequent users & $0.61(.32)^{\dagger}$ & $1.83(.98-3.42)$ & $1.26(.60)^{*}$ & $3.53(1.09-11.44)$ & $1.72(.45)^{* * *}$ & $5.59(2.30-13.61)$ \\
\hline Model constant & $-10.01(1.81)$ & .00 & $-9.62(1.81)$ & .00 & $-10.15(1.83)$ & .00 \\
\hline
\end{tabular}

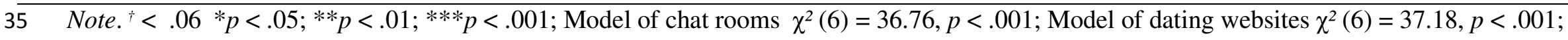

36 Model of erotic contact websites $\chi^{2}(6)=45.76, p<.001$

37 